\title{
Estudos feministas e cidadania plena
}

Adriana Bebiano e Maria Irene Ramalho

\section{(2) OpenEdition}

\section{Journals}

Edição electrónica

URL: http://journals.openedition.org/rccs/3659

DOI: $10.4000 /$ rccs.3659

ISSN: 2182-7435

\section{Editora}

Centro de Estudos Sociais da Universidade de Coimbra

Edição impressa

Data de publição: 1 junho 2010

Paginação: 5-10

ISSN: 0254-1106

\section{Refêrencia eletrónica}

Adriana Bebiano e Maria Irene Ramalho, «Estudos feministas e cidadania plena », Revista Crítica de

Ciências Sociais [Online], 89 | 2010, posto online no dia 01 outubro 2012, consultado o 21 setembro 2020. URL : http://journals.openedition.org/rccs/3659; DOI : https://doi.org/10.4000/rccs.3659 


\section{Estudos feministas e cidadania plena}

Desde que, em plena Revolução Francesa e em resposta à "Declaração dos Direitos do Homem e do Cidadão" (Déclaration des droits de l'homme et du citoyen, 1789), Olympe de Gouges escreveu a "Declaração dos Direitos da Mulher e da Cidadã" (Déclaration des droits de la femme et de la citoyenne, 1791), muito mudou na relação entre as mulheres e a cidadania. Perante a realidade social ocidental da primeira década do século XXI, muitas pessoas se interrogarão sobre a pertinência - e a oportunidade - de um debate sobre esta questão. Não estará ela, afinal, ultrapassada? Não conseguiram entretanto as mulheres o direito ao voto, à propriedade, ao corpo? Não está a igualdade jurídica consagrada na lei portuguesa, como em muitas outras? Em suma, não estão as mulheres agora incluidas no contrato social?

$A$ actualidade do debate é, no entanto, amplamente demonstrada pelo conjunto de ensaios que este número temático da Revista Crítica de Ciências Sociais inclui. Trata-se, desde logo, de redefinir o que se entende por "cidadania". De facto, esta não se esgota no direito ao voto - conquistado à custa do combate das feministas da chamada "primeira vaga" - nem sequer na igualdade perante a lei (que nem mesmo todos os Estados europeus consagram na sua plenitude). Os constrangimentos ao exercício pleno da cidadania das mulheres assumem muitas formas, que, de tão naturalizadas nas culturas (ainda) patriarcais, se tornaram invisiveis. É esta invisibilidade que é imperativo desocultar - e é justamente desse trabalho de desocultação que se ocupam vários dos ensaios aqui incluidos.

O artigo décimo da Declaração redigida por Olympe de Gouges diz que se "a mulher tem o direito de subir ao cadafalso; ela deve igualmente ter o direito de subir à tribuna". À igualdade perante a lei no que diz respeito ao castigo - à responsabilidade perante a polis e o bem comum - deve corresponder a igualdade no que diz respeito à possibilidade de intervenção na polis. Qualquer relance pelas estatísticas e pelas listas de mulheres em lugar de destaque na vida nacional - na política, nas diversas artes, nas igrejas, nas universidades - nos dirá claramente que as mulheres estão largamente ausentes. O espaço público é ainda um espaço masculino e ao masculino pertence o poder simbólico; o tempo da "dominação masculina" não é passado, mas presente. 
Que esta dominação masculina não é "natural", nem foi, mesmo no passado remoto da nossa cultura, aceite sem contestação, argumenta convincentemente Fernanda Henriques no seu ensaio "Concepções filosóficas e representações do feminino: subsídios para uma hermenêutica crítica da tradição filosófica". Importa portanto, "desnaturalizar a ideia de que a dominação masculina foi sempre pacificamente aceite." De facto, argumenta Henriques na sua abordagem panorâmica da conceptualização do feminino na tradição ocidental, "re-significar a nossa História comum, de homens e de mulheres, obriga a procurar os ruídos à aceitação universal da dominação masculina que ocorreram e trazer à luz os sinais da ambiguidade e da complexidade nas relações de poder entre os sexos, que todas as épocas testemunham." Importa agora transformar esses ruídos em voz - isto é, a fala "da tribuna" que é escutada. Porque todas as vozes são imprescindiveis na polifonia da interrogação e da resposta pelo bumano.

Dos limites da inclusão no "contrato social" - do qual Rosseau notoriamente nos excluiu - fala Carole Pateman, na sua reflexão sobre o estado actual do contrato sexual (e racial), "Garantir a cidadania das mulheres: a indiferença e outros obstáculos". Da análise da feminização da pobreza - que os estudos sociológicos demonstram - emerge a constatação da persistência da condição de "segundo sexo" que continua a caber às mulheres. O principal obstáculo à realização da cidadania, segundo Pateman, está no "contrato da indiferença mútua" pelo sofrimento alheio; e argumenta a cientista política que "o contrato sexual desempenha um papel igualmente importante no fomento da indiferença". Pateman defende uma intervenção do Estado no sentido de assegurar as condições minimas para o exercício da cidadania pela atribuição de um rendimento básico a todos os cidadãos.

Cecília MacDowell Santos também se debruça sobre a intervenção do Estado num domínio do que ainda há poucas décadas era pensado como sendo do domínio do privado: "Da delegacia da mulher à Lei Maria da Penba: absorção/tradução de demandas feministas pelo Estado" aborda aspectos da protecção das mulheres contra a violência doméstica no Brasil, desde que foram criadas as "delegacias da mulher" e promulgada a lei conhecida como Lei Maria da Penha (na sequência do caso dramático de uma vítima de violência com este nome). À necessidade da protecção por parte do Estado contrapõe-se a análise dos mecanismos que produzem novas formas de regulação.

A precariedade da identidade das mulheres num contexto global governamental e pós-colonial nunca será tão evidente como nas migrações forçadas e nas grandes e cruéis diásporas do nosso tempo. O artigo de Teresa Cunha, intitulado "Imobilidades e fracturas: mulheres, identidades e narrativas viajantes em Timor-Leste", debruça-se sobre a reconfiguração da identidade de algumas 
mulheres diaspóricas de Timor-Leste, empenhadas na produção de identidades e narrativas viajantes, capazes de dialogar com uma construção feminista e pós-colonial da nova nação. A preocupação de Teresa Cunba é assinalar a importância da participação activa das mulheres nos processos emancipatórios, mesmo em condições de subalternidade. As histórias de vida recolbidas pela autora são testemunho gritante da discriminação de que continuam a ser vítimas as mulheres, sobretudo em situações de extrema dependência e mesmo em contextos revolucionários. Por isso, mais de salientar e louvar as lutas em que se empenham e os resultados positivos que vão conseguindo.

Dos combates feministas - como de outros - sabemos que são feitos de fluxos e refluxos. Um olhar sobre a história revelará que, a cada momento de afirmação das mulheres no espaço público, se seguem medidas de regulação que as remetem de novo para a sombra, ainda que noutros moldes. Assim, as leis napoleónicas que se seguiram aos tempos da Revolução Francesa; assim as leis do Estado Novo que se seguiram à emancipação permitida - e o uso da palavra é deliberado - pela $1^{a}$ República em Portugal. Assim os anos de 1980 depois da implosão libertária da Revolução de Abril de 1974 em Portugal. Em "Lésbicas portuguesas no século vinte: apontamentos para a História", Dee Pryde argumenta justamente a existência actual de um retrocesso no que aos direitos das lésbicas portuguesas diz respeito. O controlo do patriarcado sobre as mulheres passou desde sempre muito pelo controlo dos seus corpos. Pensada como apenas receptáculo da semente criadora (masculina) por Aristóteles, e por útero que garantia a passagem da propriedade aos filhos legítimos do Pater Familias, desde a antiguidade até à instauração da moral burguesa, o corpo das mulheres é, literal e simbolicamente, do homem. Não surpreende, portanto, que uma das reivindicações feministas importantes tenha sido justamente o "direito ao corpo", seja pelo controlo da reprodução, seja pelo exercício da sexualidade plena, com direito ao prazer próprio. Estas lutas, no entanto, pressupunbam durante muito tempo a "beterossexualidade compulsória", de que fala Adrienne Rich. A opção pelo "amor sáfico" não se coloca num universo falocrático; se apenas o pénis significa sexualidade, as "mulheres que amam mulheres" estão condenadas à invisibilidade. Uma vez visivel esta orientação sexual, no entanto, argumenta Pryde, ela continua subsumida num universal neutro - "bomossexual" - isto é, sendo ainda o macho "o sexo-que-é", a mulher (lésbica) não é senão uma mera variante que em relação a ele se define. A história das lésbicas portuguesas está por fazer. O mérito do artigo de Dee Pryde consiste precisamente em começar a esboçar essa história.

Uma outra história que tem vindo a ser contada com cada vez mais pormenor e rigor é a história da relação entre as mulheres e as artes, designadamente a pintura e a escultura. Deste tema se ocupam Angélica Lima Cruz 
e Maria José Magalhães, em dois artigos independentes, porém interligados. Em "O olhar predador: a arte e a violência do olhar", Cruz passa em revista a história de arte ocidental, dominada pela violência de um olhar masculino e sexista, que objectifica as mulberes nas imagens que delas cria. Sublinhando a necessidade de uma perspectiva feminista que tome em consideração os contextos e condicionalismos da produção artística, à qual só muito recentemente as mulheres começaram a ter acesso, e salientando o facto de as mulheres terem sido abundantemente representadas ao longo dos tempos, mas raramente terem representado e mais raramente ainda se terem representado a elas próprias, Cruz conclui pela necessidade de uma crítica feminista que dê conta dos viezes do cânone e da tradição, bem como de todos os prejuizos sobre sexo, classe, raça, sexualidade e subjectividade, de que continuam a enfermar as concepções hegemónicas de criatividade e representação no Ocidente.

Na sequência lógica do artigo anterior, e de igual modo magnificamente acompanhado de ilustrações muito oportunas, o ensaio de Maria José Magalhães retoma a questão da cultura de violência contra as mulheres, que é a nossa (e que só este ano já reclamou 23 vidas), passando a explorar algumas das formas artísticas de intervenção feminista, em que este tipo de violência é exposto. Em "Activismo feminista e desconstrução da violência contra as mulheres", analisando algumas intervenções artísticas e instalações realizadas por feministas, quer no estrangeiro quer em Portugal, Magalhães mostra como a crítica feminista da violência contra as mulheres desoculta os mecanismos da sua reprodução, sugerindo ao mesmo tempo que a arte pode constituir-se como processo de desconstrução. A arte, articulada com uma política feminista, conclui Magalhães, pode ser um instrumento poderoso de transformação social, começando, como defende também Griselda Pollock, por reinventar um tipo de espectador completamente novo e liberto do sexismo violento da cultura que nos tem regido.

O olhar feminista sobre as artes da literatura é bem mais antigo e desde sempre interdisciplinar. Em "O conteúdo da forma e outras políticas textuais: configurações de nação e cidadania em Disgrace e Agaat", Rosemarie Buikema debruça-se sobre dois celebrados romances da África do Sul pós-apartheid, para entender as formas como a literariedade e as políticas de representação se conjugam para a construção da identidade e da diferença, da comunidade e da cidadania. Observando os contextos e circunstancialismos da publicação tanto do romance de J. M. Coetzee (Disgrace, 1999) como do romance de Marlene van Niekerk (Agaat, 2006), e analisando a recepção polémica de cada um deles, Buikema sugere que, não apresentando soluções para as questões relacionadas com a política da identidade ou outras, a literatura "traz questões como estas 
para primeiro plano, contando bistórias e situando personagens em diversos tempos e lugares". Romances complexos e controversos, como Disgrace $e$ Aggat, em que às representações das mulheres cabe ainda a designação, que gostaríamos ultrapassada, de "segundo sexo", constituem, conclui Buikema, guias preciosos para uma "exploração mais aprofundada da interacção de forma e conteúdo, literariedade e política, literatura e cidadania".

Como transparece já do artigo anterior, o "segundo sexo" não encontra apenas tradução em práticas sociais: tem uma raiz simbólica profunda, pelo que importa desconstruir as representações, e que muitas das lutas presentes passem por uma releitura do passado, por uma hermenêutica de desocultação dos significados dominantes. Em "A ironia ovidiana na subversão do protocolo amoroso em Roma", Carlos André revisita Ovídio, em cujos poemas é possivel ver a ambiguidade da Roma antiga em relação às mulheres: se as leis $e$ as práticas sociais thes cerceavam os direitos e as confinavam ao gineceu, as representações reconbecem-lhes dimensões ausentes do discurso público dominante. A subjectividade das mulheres, expressa em Ovidio na paridade da relação amorosa - isto é, no exercício do direito ao seu corpo -, é exemplar dos ruidos marginais, mas que não deixaram de ser articulados ao longo da bistória da nossa cultura.

O mesmo se poderia dizer dos textos bíblicos e patrísticos que fundam a religião cristã (católica), como resulta claro do trabalho de Teresa Toldy sobre esta matéria. O ensaio aqui incluído, que a teóloga intitula "A violência e o poder da(s) palavra(s): a religião cristã e as mulheres", mostra bem como as palavras do cânone religioso foram e são utilizadas para subalternizar as mulheres e sobre elas legitimar a violência patriarcal. Socorrendo-se, no entanto, da teóloga feminista americana Elisabeth Schüssler Fiorenza, Toldy conclui, apontando caminhos, que também ela apelida de "ruidosos", para a subversão dos discursos hegemónicos de poder. As recentes intervenções de Toldy na polémica sobre a ordenação sacerdotal das mulheres fazem parte desse necessário ruído subversivo, o qual cada vez mais clama para ser ouvido como autêntica voz cidadã, de pleno direito.

Habitar autonomamente a cidade, ser, de pleno direito, parte da cidade e a ela juntar uma voz própria - é isso a cidadania plena. O que de modo algum implica a eliminação de todas as diferenças, e muito menos a eliminação da diferença sexual. O pensamento feminista mais recente, de inspiração neomaterialista, e de que dá conta o ensaio de Isabel Allegro de Magalhães, recupera o fundamento corpóreo do sujeito, obrigando a repensar a diferença sexual em ligação com novas modalidades de articulação com o não-bumano, o mundo animal, as biotecnologias, a tecnociência e a biosfera. Em "A instância corpórea do bumano: sexualidades e subjectividades, mulheres e ética", em larga 
medida inspirada no pensamento deleuziano e espinosista de Rosi Braidotti, Magalhães pergunta-se se "o apagamento da diferença sexual não representará mais uma perda na diversidade bumana". À sua própria perplexidade, a que Braidotti dera já resposta naquilo a que chamou "a positividade da diferença", contrapõe Magalhães quatro "vozes", duas delas miticas, através das quais, segundo a autora, será possivel repensar a diferença sem secundarização ou opróbrio, superar a "feminidade clássica" e ultrapassar "a maternidade patriarcalmente definida".

Este número temático da Revista Crítica de Ciências Sociais encerra com um belo ensaio de Ana Luísa Amaral. Poeta amplamente premiada e ainda respeitada teórica e crítica de poesia, feminista e especialista de estudos feministas, Ana Luisa Amaral oferece neste bíbrido de poética e ensaística, que sugestivamente intitula "Os teares da memória", uma reflexão exemplar sobre as palavras da sua própria criatividade como poeta, uma poeta que é, podemos afirmar, com as teorias da performatividade queer em mente, muito mais do que uma simples mulher-poeta. Escrupulosamente atenta à sua própria condição humana e às suas várias identidades e contextos, esta poeta de avessos e desavessos (na consciência de que a língua diz de mais e de menos ao mesmo tempo) assume por inteiro o compromisso de fazer "rimar obrigação cívica com insurreição poética". "Para mim, que os escrevo", pondera a autora a dada altura, "os poemas exprimem a angústia da própria escrita e a inadequação sempre da palavra e, por isso mesmo, o seu poder, o que permite 'a primeira bumana / construção: // invenção reticente / da palavra / sublime e poderosa arte / da mentira'”. Impossivel não lembrar as palavras daquele Luiz (de Camóes) reinventado por Ana Luísa Amaral na recente peça, intitulada Próspero morreu, a mulher-poeta na voz da Ariadne-do-Fio, igualmente reinventada, a problematizar as certezas da epopeia nacional: "Falo [...] / de assombros e de escarpas, / de borizontes lançados sobre o nada. // E falo ou minto? / Quando escrevo de luzes sobre adamastores, / de mombaças fingidas, tágides de tais cores / que a garganta se pára, paralela, / e ao seu lado, o dizer?"

Uma das grandes preocupações da "terceira vaga do feminismo" é, nas palavras de Drucilla Cornell, invocando Marie Cardinal, les mots pour le dire. Os ensaios recolbidos neste número são um contributo significativo nesse sentido. Só rejeitando o discurso patriarcal hegemónico que há séculos as vem dizendo, só dizendo-se elas mesmas sujeitos da cultura, conquistarão as mulheres finalmente o seu lugar próprio e pleno na cidade dos bumanos e de todos os seres.

Adriana Bebiano

Maria Irene Ramalho 